\title{
Development of Potassium Polytitanates Nanoadsorbents for the Removal of Lead lons from Water - Dynamic Processes
}

\author{
Aguilar González Miguel Ángel \\ Centre for research and advanced studies of national polytechnic. Cinvestav Saltillo \\ México
}

\section{Introduction}

Lead $(\mathrm{Pb})$ is a toxic element that accumulates in the body by inhaled air or ingested in food or water. Lead has been used for centuries to make water pipes and cooking utensils. In fact, lead is a very rare element in the lithosphere. Lead is one of the heavy metal that has a great number of applications in industrial activities that are necessary to life and its contact effects have been studied by some of researchers. Lead is present in applications such as: manufacture of accumulators, centralized waste landfill, copper smelter, electric-electronic components, electrowinning, inorganic chemicals, cast iron and steel, metal finishing, fusion and metal forming, powder metallurgy ferrous and non-ferrous, non-ferrous metal casting, organic chemicals plastics and synthetic fibers, chemical pesticides, storage batteries, antiknock gasoline, pigments porcelain enamel, plastics manufacturing, electricity generating by steam, transportation of cleaning equipment and combustion wastes. All these applications are due to its physicochemical properties than allows it to be compatible and shape easily to others materials with modified properties. It can be mixed with other metals to form useful materials. Most of these materials can be largely recovered, so that lead can be recycled. The environmental threat comes from the one used in chemical compounds.

Its asymptomatic presence is one of the most important aspects in different diseases and also of environment caused by its contact or consumption of waters with low contents of this element (Naicker et al, 2010, Albalak et al, 2003 \& Noona et al, 2001 ). There is great concern in cities of underdeveloped countries on five continents by the fact that lead influence in the human body can develop: anemia, kidney disease, brain damage, impaired nervous system function peripheral, high blood pressure, reproductive abnormalities, developmental defects, abnormal metabolism of vitamins, low intelligence quotient and sometimes death, (Hrudey et al., 1995 USEPA, 1992). The greatest concern that its presence there affects mainly children under 6 years and unborn babies (Zhang et al., 2005, Naicker et al., 2010, \& Riddell et al., 2007). On the other hand, lead plays an important role in the food chain and is of vital environmental importance because it alters the ecosystems and natural soils(Tong et al, 2000).

The lethal dose of lead absorbed is estimated at $0.5 \mathrm{mg}$. The accumulation and toxicity appear if was adsorbed more than $0.5 \mathrm{mg}$ per day. The half life of lead in bone is 32 years and in the kidney of 7 years. The exposure limit for lead in air is $0.15 \mathrm{mg} / \mathrm{m}^{3}$. The exposure 
limit for lead in food is $2.56 \mathrm{mg} / \mathrm{kg}$ according to The U.S. Centers for Disease Control and Prevention (CDC) who has defined an elevated blood lead level (BLL) as 10 micrograms per deciliter $(\mathrm{mg} / \mathrm{dl})$.

Recently Potassium Polytitanates $\left(\mathrm{K}_{2} \mathrm{Ti}_{n} \mathrm{O}_{2 n+1}\right)$ have been recognized like functional advanced materials and adsorbents of metallic ions(Tan et al., 2007), they can be present with different behaviors e.g. with relationships among $n=4$ to 6 they present adsorption and ion exchange properties (Wang et al, 2009) and with relationships between 6 to 8 they could be present excellent mechanical properties (Bavykin et al., 2006). Microstructure is influenced by this relationship for $\mathrm{K}_{2} \mathrm{Ti}_{4} \mathrm{O}_{9}$ layer morphology regularly is presented, fibers, whiskers or cylindrical forms to $\mathrm{K}_{2} \mathrm{O} \bullet 6 \mathrm{TiO}_{2}$ or $\mathrm{K}_{2} \mathrm{Ti}_{6} \mathrm{O}_{13}$ (potassium hexatitanate). Potassium polytitanates have been applied like raw materials to fabricate ceramics (filters, barriers, high temperature sensors (Gratzel, M., 2001; Fox M. A \& Dulay M. T., 1993), and their excellent mechanical and frictional properties are useful for their application as:reinforcing additives, as well as, antifriction properties(Zhuang et al., 2007) in different materials. Low friction coefficient has shown that they could be excellent applications as solids lubricants and frictionant materials (Xie et al., 2010). Additionally its low thermal conductivity and its high reflectance at the ultraviolet range, near to infrared region favors its application in manufacture heat resistance materials, also as isolating of materials and coatings.

To counteract lead pollution of air, soil and water adsorbents have been developed based on activated coal (Ayyapan et al., 2005), biological mixture(TSezos., 1984), ion exchange resins(Matsumiya et al., 2003), (Plaza et al., 2009), and natural or synthetic zeolites(Barrier, 1978) which ones intended to diminish the concentration of lead in solution. Limitations such as high cost of synthesis reactors, processing equipment and maintenance, long times adsorbent synthesis, bogged down process, complications for storage the exhaust adsorbents all of these reasons generate the necessity to develop adsorbents that combine excellent adsorption properties, low cost, high efficiency, short and immediate processes and a post-treatment or confinement environmentally safe.

For this reason in this research has been synthesized PPN (Potassium Polytitanates Nanoadsorbents) as effective adsorbents of lead in contaminated water.

Among several chemical routes available for the synthesis of nanoadsorbents materials, molten salts technique has been proved to be very promising due to its uniqueness in being facile, cost effective, environmentally benign and crystalline regulated in order to adsorption applications (Afanasiev, 2006).

Below are described some investigations which have involved different techniques for obtaining nanomateriales with interesting adsorption properties.

\subsection{Alkaline titanates synthesized by different techniques 1.1.1 Soft chemical route}

One method to obtain layered alkali titanates in nanometric scale is the called soft chemical route, which is a type of chemical reactions used at room temperature in open systems, based on polymerization reactions in which a molecular precursor solution becomes a chemical reaction and subsequently dried and densified into a solid material with properties different from that of the starting materials. Riss et al., 2007 adjusted the photoelectronics properties of layered titanates nanostructures by changing the nature and bonding state of ions in the interlayer region studies. Also they have shown that a facile ion exchange behavior in titanates nanostructures control these properties by interactions in the interlayer region. 
It is well known that cationic ions that exist in the structure of the titanates are weakly attached to each interlayer channel (Unal, et al, 2003); therefore the adsorption and ion exchange properties are due to that the distances more higher between alkali ions negatively charged and the oxygen ions than those distances of protons and octahedral oxygen ions. Zhang et al., 2005 proposed that the protonation of the $\mathrm{TiO}_{6}$ block influences the electron density in the moiety of the Ti-O to the $\mathrm{OH}$ bonds leading to an increase in the length of adjacent Ti-O bond.

\subsubsection{Hydrothermal synthesis route}

The hydrothermal synthesis appeared in the decade of the 80's and was proposed as a method of synthesis of crystalline ceramic materials with high purity features. Through this method can be obtained high-quality crystals without the need of routines of grinding or a further heat treatment of materials, using low surface area powders and high pressures at temperatures below $200^{\circ} \mathrm{C}$. Besides exploits the reactivity of powders with low specific surface areas. Some types of zeolites and titanates as adsorbents for various applications have been synthesized (Hayashi, H. \& Hakuta, Y. 2010).

Yang et al., 2010 prepared layered titanates nanofibers and sodium titanates and sodium titanates in acid form by hydrothermal synthesis, they studied these materials as adsorbents for removal of toxics radioactive $\left(\mathrm{Sr}^{2+}, \mathrm{Ba}^{2+}\right.$ as substitute of $\left.226 \mathrm{Ra}^{2+}\right)$ and heavy metals ions from water $\left(\mathrm{Pb}^{2+}\right)$. This method consists in mixing hydroxides and titanium compounds under hydrothermal conditions. So two aqueous solutions containing salts are mixed y treated during 2 days in an autoclave at $245^{\circ} \mathrm{C}$ (hydrothermal reaction) to yield titanates fibers. The solid after drying at $178^{\circ} \mathrm{C}$ during $6 \mathrm{~h}$ in the mixture can be recovered and washed with deionized water. They can convert to trititanate to a new phase $\mathrm{Na}_{1.5} \mathrm{H}_{0.5} \mathrm{Ti}_{3} \mathrm{O}_{7}$. The chemical equation for this transition is:

$$
2 \mathrm{Na}_{2} \mathrm{Ti}_{3} \mathrm{O}_{7}+\mathrm{H}_{2} \mathrm{O} \rightarrow 2 \mathrm{Na}_{1.5} \mathrm{H}_{0.5} \mathrm{Ti}_{3} \mathrm{O}_{7}+\mathrm{NaOH} \quad \text { at } 250^{\circ} \mathrm{C}
$$

\subsubsection{Sol-gel synthesis route}

Sol gel Route it is described as a structural synthesis from drawing upon particles in solution (Schmidt et al., 2010). It's similar to the precipitation route but different due in this method is more stable the environment inside of the solution as result of chemical interactions. The conventional agglomerated sizes are presented around of 1-100 nm. The overall sol-gel process can be described in four stages: a) homogeneous precipitation (kinetic control), b) Initial nucleation where by decomposition of compounds it is release the necessary precursors to particle precipitation, c) metallic hydrolysis or deprotonation of hydrous metal oxides and d) control of parameters that influences in the hydrolysis as such as: control of the temperature, concentration, and $\mathrm{pH}$ of the solution. Finally hydrolysis process is promoted by compounds chemical interactions as organic liquids which ones $\mathrm{OH}^{-}$ ions in systematical form.

\subsubsection{Calcinations synthesis route}

In this technique analytical-grade reagents as $\mathrm{KF}$ and $\mathrm{TiO}_{2}$ (anatase or amorphous gel) are used as starting materials. Afterward powders are dried at $720^{\circ} \mathrm{C}$ for $20 \mathrm{~min}$ before being mixed. The weight ratio of $\mathrm{KF}$ to $\mathrm{TiO}_{2}$ in the mixtures can adjusted to various values, to investigate the influences of weight ratio on the formation of titanates whiskers. Powders 
are mixed homogeneously to form a precursor powder and then put into a furnace. The heat treatment is basically fixed at $720^{\circ} \mathrm{C}$ for $4 \mathrm{~h}(\mathrm{Li}$ et al., 1999).

\subsubsection{Molten salts synthesis route}

The synthesis method of molten salts, is the fusion of salts to solubilize reagents that lead to better dissemination of materials and reduced the reaction temperature. The term "Molten Salt" is self-descriptive; it is melted salt(s). The molten salt fusion is usually performed in a temperature range from 200 to $600^{\circ} \mathrm{C}$. When liquid is stable, has a heat capacity similar to water (by volume) and flows much like water does. In this method it loses the difference between "solvent" and "solute" in the sense that the flux must provide atoms or structural building units ending in a final crystal product or "quasi-crystalline". Moreover, the chemical properties of flux, as the acidity and redox potential, have a controlling influence on the nature of the products. Salts are simple, usually ionic (that is the chemical bonds are a simple ionic type) and stable compounds. The most common example of which is "table salt", or sodium chloride $(\mathrm{NaCl})$. Both sodium and chlorine are notoriously reactive; sodium is one of the most electropositive substances (wants to lose an electron) and chlorine one of the most electronegative (wants to take an electron). These two opposite substances readily join to form stable sodium chloride via a strong ionic bond.

\subsection{Potassium polytitanates nanoadsorbents obtained by molten salts route}

Unique properties and behavior different among the oxides family, potassium polytitanates are a large class of semi-crystalline titanates materials, arrangements in their lamellar or stringy nanostructures, uniformly linked and with interlayer spaces between them. Also the exfoliation and intercalation could be properties present in this kind of materials (Unal et al., 2003).

The procedure for obtaining powders by molten salt consists as follow: $\mathrm{TiO}_{2}$ powders were mixed with $\mathrm{KNO}_{3}$ and $\mathrm{KOH}$ and then heated to a temperature range from 450 to $550{ }^{\circ} \mathrm{C}$ and afterward treated for a period of time 1 hour. The synthesized powders should be washed (purified) with distilled water and separated with a filter paper. Finally the powders are treated inside furnace at a temperature of $90^{\circ} \mathrm{C}$ during 2 hours. Complete description for the potassium polytitanates is given in the experimental part of this chapter.

However, the fibrous powders have a bulky nature, poor fluidity, and inconvenience in handling. Thus, in spite of their attractive properties, fibrous potassium titanates are difficult to use to produce ceramic green bodies by conventional ceramic technologies and require very high pressures. Moreover, the fibrous powders tend to cause dusting, which represents a health risk in the working environment; the fibrous morphology of some potassium titanates has been associated with carcinogenicity. For these reason in this work potassium polytitanates nanoadsorbents were bonding with potato starch according previous studies (Gregorová et al, 2008). Potato starch was used to bind the nanoadsorbent and generate porous structure due that is an organic material with an ash content low to negligible (at least from the standpoint of materials science.) This is above the sintering can say that the end products of starch will always be $\mathrm{CO}_{2}$ and $\mathrm{H}_{2} \mathrm{O}$, provided that during the burning is conducted in an oxidizing atmosphere. Of course, under reducing conditions may occur residual carbon. The potato starch breakdown begins to be detected below $300^{\circ} \mathrm{C}$ (Laurentin et al., 2003).

Molten salt through the following reaction is proposed: 


$$
\mathrm{KNO}_{3}+\mathrm{KOH}+\mathrm{TiO}_{2} \quad 500 \rightarrow \mathrm{KTiO}_{3}+\mathrm{CO}_{2}
$$

In this work, we describe the preparation and characterization of nanoadsorbents of potassium polytitanates produced by the molten salt synthesis which ones contain both combined structures potassium titanate. Figure 1.
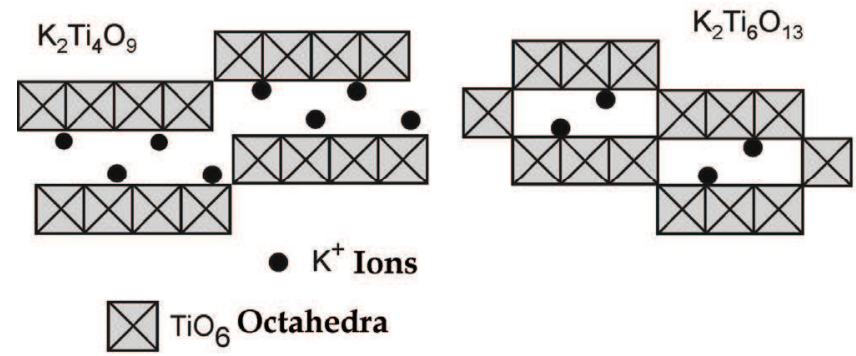

Fig. 1. Idealized structural arrangements from $\mathrm{K}_{2} \mathrm{Ti}_{4} \mathrm{O}_{9}$ (potassium tetratitanate) and $\mathrm{K}_{2} \mathrm{Ti}_{6} \mathrm{O}_{13}$ (potassium hexatitanate).

\section{Experimental part}

Nanoadsorbents of potassium polytitanates were produced with $\mathrm{KNO}_{3}$ (Merck brand with 98.9\% of purity), $\mathrm{KOH}$ ( brand Aldrich with flakes form and Powdered $\mathrm{TiO}_{2}$ (anatase of purity of $99 \%$, with average particle size of $3 \mathrm{~mm}$ brand Aldrich, Milwaukee, WI) in a relationship of 8.2:1.0:0.8 all of them were treated, using Steel Stainless crucibles $(750 \mathrm{ml}$ of capacity). First stage consists of treat in molten mixtures $\mathrm{KNO}_{3}$ y $\mathrm{KOH}$. The synthesis was carried out in an electric muffle furnace (Thermolyne 27000), 500 $\mathrm{C}$ for $1 \mathrm{~h}$ in air atmosphere compounds. Afterward having reached a temperature of 500 was added to the $\mathrm{TiO}_{2}$ anhydrous. Preliminary tests showed that this time was sufficient to obtain products consisting mainly of potassium titanates with some of un-reacted $\mathrm{TiO}_{2}$. The ideal time of heat treatment of this technique to produce pure potassium titanates is three hours, but this option was rejected for economic and energy saving reasons. After that molten material was separated, in this stage soluble compound were separated of the solid material. Nanoadsorbents fine powders were washed in distilled water to dilute any remaining of soluble nitrates and chlorides in the molten salt mixture, these powders were washer using $1000 \mathrm{ml}$ of bidistilled water for each $250 \mathrm{~g}$ of powders and then were filtrated with paper Whatman No. 42 four times each set. The ultimate suspension was ultrasonically treated (Fisher Scientific, Model 550, USA) for $30 \mathrm{~min}(80.75 \mathrm{~kW}$ at $20 \mathrm{kHz})$ and filtrated. The powders thus obtained were finally dried for $2 \mathrm{~h}$ at $90^{\circ} \mathrm{C}$.The dried powders Were used directly and also in granular form as adsorbent material in adsorption columns. Thermal events of nanoadsorbents powders and their dehydration processes were investigated by thermal analysis, (TGA/DTA, in Perkin Elmer, Pyris Diamond instrument).

Phase composition of nanoadsorbents were analyzed by X-ray diffractometry (XRD, Philips $X^{\prime}$ Pert using CuKa radiation with a nickel filter, with the continuous scan mode at 51-601 $2 \mathrm{y}$ at a rate of $0.0212 \mathrm{y} / \mathrm{s}$; the operation conditions were: $40 \mathrm{kV}$ and $100 \mathrm{~mA}$. The reflection positions and relative intensities were referred to the International Center for Diffraction Data (ICDD-2004). Quantitative XRD analysis was carried out to determine the $\mathrm{TiO}_{2}$ contents in the PTP, using $\mathrm{TiO}_{2}$-anatase phase as an internal standard. 
The kinetics of adsorption of $\mathrm{Pb}$ (II) present in aqueous solutions was determined by an atomic emission spectrometer (ICP, Thermoelemental Thermojarrel Ash model Iris Intrepid II). The spectrometer was calibrated with NIST certified standards.

The specific surface area was determined on a sorptometer (Quantachrome Autosorb1C, Asicxtcd6) using the principle of adsorption/desorption of a monolayer of nitrogen on the surface of the solid, based on the methods of Brunauer-Emmett-Teller (BET) and micro-pores analysis. The pore size distribution was investigated by mercury intrusion porosimetry (MIP Pore Master 60 GT). IUPAC (International Union of Pure and Applied Chemistry) classification was used to identify the porosity of the samples characterized. On the other hand, isotherms were adjusted according.(Gregg and Sing, 1952: Rouquerol et al., 1994)

The observations and energy dispersive X-ray spectroscopy (EDS) patterns of nanosorbents were obtained of the scanning electron microscopy (SEM) were carried out in a XL30-ESEM FEI Philips instrument, operating at $20 \mathrm{kV}$. Transmission electron microphotographs (TEM), high-resolution transmission electron microphotographs (HRTEM), selected-area electron diffraction (SAED) in a TEM Titan 80-300 FEG is a high-resolution analytical transmission electron microscope operating at $200 \mathrm{kV}$. The sample for TEM/HRTEM observations was prepared by deposition of a drop of the colloidal dispersion of $\mathrm{K}_{2} \mathrm{Ti}_{6} \mathrm{O}_{13}$ onto 200 mesh $\mathrm{Cu}$ grids coated with a carbon layer.

Fact Sage software has been used to predict and of to calculate phases than could precipitate and phase transformation during adsorption processes in the aqueous system.

Figure 2 shows processing stages of manufacturing process of potassium polytitanates nanoadsorbents.

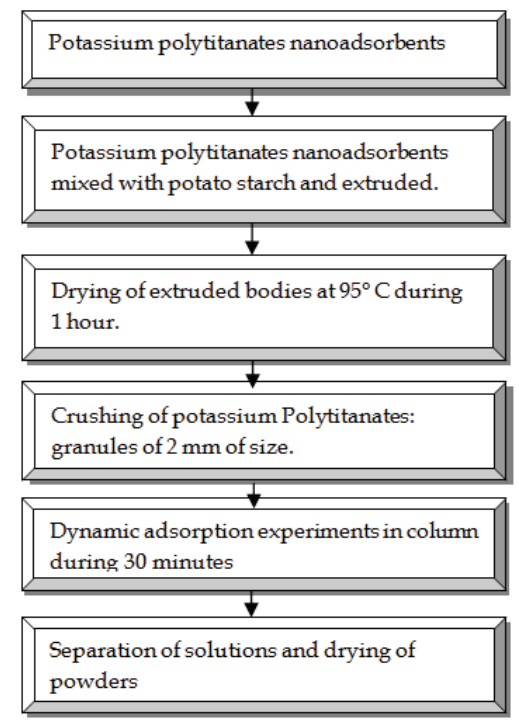

Fig. 2. Flow chart of manufacturing process of potassium polytitanates nanoadsorbents.

\subsection{Materials}

For the fixed-bed experiments, potassium polytitanates nanoadsorbents were prepared in the form of granules. 


\subsubsection{Solutions}

The initial metal stock solution was prepared from the nitrate salt, $\mathrm{Pb}\left(\mathrm{NO}_{3}\right)_{2} \cdot 6 \mathrm{H}_{2} \mathrm{O}$. All chemicals were reagent grade and they were used without further purification. All solutions were prepared with deionized water and the glassware was cleaned by soaking in $10 \% \mathrm{HCl}$ and rinsed with water. The background electrolyte was potassium nitrate.

$\mathrm{pH}$, adsorbent dose and concentration of the solutions were selected considering that the $\mathrm{pH}$ of operation of polytitanate potassium in nanoasorbentes is 10.24 (stable after 24 hours) this was based on previous studies and preliminary evidences of PPN electrochemical studies than were performed.

According to these electrochemical studies that were carried out in the nanoadsorbents and research made by Dean et al, 1972, $\mathrm{pH}$ values for precipitation of lead in dilute solutions is located close to 6 (Table 1). These values were considered for the systematization and synchronization of the experiments, as well as taking the value of 3.5 which is a real industrial value in the treatment of lead wastewaters. In the table 1 are presented $\mathrm{pH}$ values of precipitation of different bivalent metallic ions.

\begin{tabular}{c|c|}
$\begin{array}{c}\text { Precipitation values } \\
\text { in diluted solutions }\end{array}$ & $\mathbf{p H}$ \\
\hline $\mathbf{F e}^{3+}$ & 2.0 \\
$\mathbf{A l}^{3+}$ & 4.1 \\
$\mathbf{C r}^{3+}$ & 5.3 \\
$\mathbf{C u}^{2+}$ & 5.3 \\
$\mathbf{F e}^{2+}$ & 5.5 \\
$\mathbf{P b}^{2+}$ & 6.0 \\
$\mathbf{N i}^{2+}$ & 6.7 \\
$\mathbf{C d}^{2+}$ & 6.7 \\
$\mathbf{Z n}^{2+}$ & 7.0 \\
$\mathbf{H g}^{2+}$ & 7.3 \\
$\mathbf{M n}^{2+}$ & 8.5 \\
$\mathbf{C o}^{2+}$ & 6.9 \\
\cline { 2 - 2 }
\end{tabular}

Table 1. $\mathrm{pH}$ values of precipitation in dilute solutions. (Dean et al 1972).

\subsubsection{Determination of the columns features}

Lead nitrate used in adsorption tests (Aldrich, 99\% purity) was an aqueous solution with a concentration of $155 \mathrm{mg} / \mathrm{dm} 3$, using distilled water and $\mathrm{pHo}=5.5$ without initial $\mathrm{pH}$ adjustment. Then the solutions were stirred for a period of 30 minutes at $120 \mathrm{rpm}$, with the aid of a magnetic stirrer Corning brand. This solution, No. 1, was used in direct adsorption tests. Additionally, solution 2 was prepared by mixing 1 with nitric acid (1M) for a $\mathrm{pH} 0=3.5$. Both solutions were used to investigate the influence of $\mathrm{pH}$ on the effectiveness and mechanism of removal of $\mathrm{Pb} 2+$ of acidic solutions, usually produced as industrial waste

Dean et al, 1972. $\mathrm{pH}$ measurements were made with a $\mathrm{pH}$-Meter, Make plusmeter Orion Model 420, with a glass electrode Thermo brand. 


\subsection{Column adsorption conditions}

All experiments were conducted at $25 \pm 2{ }^{\circ} \mathrm{C}$. Pyrex ${ }^{\circledR}$ glass column with the dimensions of $25 \mathrm{~mm}$ in diameter and volume $\mathrm{Vc}_{\mathrm{c}}=75 \mathrm{~cm}^{3}$, which was filled with $165 \mathrm{~g}$ of adsorbent granules (with sizes from 2 to $3.5 \mathrm{~mm}$ ), occupying a volume of $\mathrm{Vo}=70 \mathrm{~cm}^{3}$. Granules in turn were supported by a stainless steel mesh (standard mesh \# 325) of $24 \mathrm{~mm}$ of diameter, not to drag all this fine material produced during the elution process. The top of the column was covered with a lid that contains a connecting tube to remove air bubbles. Flow of metal solutions was controlled by a valve located at the bottom of the column. Others research have applied fiberglass to support the materials adsorbents. In this work, previous studies were conducted (with distilled water only) to determine the flow rate of solutions through the porous ceramic adsorbents. The optimum rate was determined at $70 \mathrm{ml} / \mathrm{min}$, this was made trying to consider bibliographic information found for columns packed with activated carbon and porosity content in the adsorbents.

The corresponding aqueous solution was added with a burette to the adsorbent, to control the rate of delivery. The initial rate of elution corresponded to a value of $2 \mathrm{Vo} / \mathrm{h}\left(140 \mathrm{~cm}^{3} / \mathrm{h}\right)$, this rate is within the typical values for industrial adsorption columns (Klein 1985) and samples were monitored and passed through the adsorbent at different times $(0,2,5,11,20,37$ and 40 hours.). The aqueous solution was poured into to the column using a system of two attached vessels located over the column with a stable hydrostatic pressure of liquid (Figure. 2). To determine the elution rate, the solution was passed through the column and collected in samples of $100 \mathrm{~cm}^{3}$, which determined the $\mathrm{pH}$ (Orion potentiometer 420) and the contents of $\mathrm{K}$ and $\mathrm{Pb}$ by ICP spectrometry (Thermoelemental Thermojarrel Ash, Iris Intrepid II).

The results of $\mathrm{Pb}$ and $\mathrm{K}$ in each period were evaluated by chemical analysis technique of atomic absorption spectrophotometry in order to study the mechanisms of reaction column and also $\mathrm{pH}$ of solutions were determined in each of the different samples. The amount added in this device was enough to supply each experiment by 40 hours continuously.

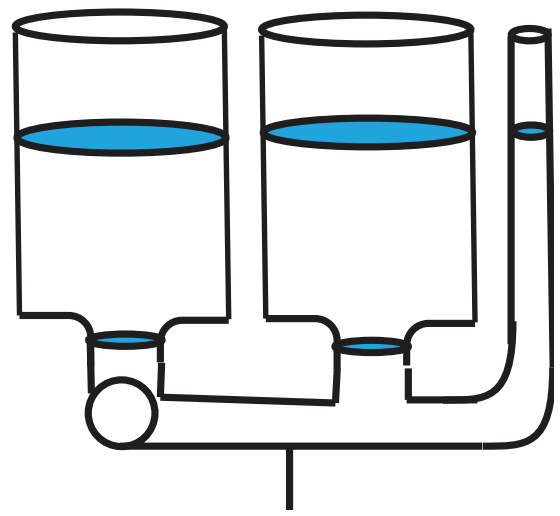

Fig. 3. Schematic representation of the attached vessels for dynamic adsorption experiments on lead removal by potassium polytitanates nanoadsorbents.

All experiments were performed independently for each condition of $\mathrm{pH}$ and concentration. The maximum time of pass of the lead nitrate solutions was 40 hours (adsorbents saturated), then the adsorbents were removed from the column, dried at a temperature of $60^{\circ} \mathrm{C}$ for one 
hour. These adsorbents were characterized by the techniques of SEM, XRD, thermal analysis, IR and specific surface area.

Operating conditions in the dynamic adsorption experiments in columns for aqueous solutions of lead are summarized in Table 2. This work has applied a method based on the originally described by Michaels et al., 1952 for ion exchange resins and subsequently by Weber, 1972 \& Lukchis, 1973, for activated carbon beds.

\begin{tabular}{c|c} 
Property/Feature & Inorganic Media \\
\hline Agglomerate Size & $0.25-3 \mathrm{~mm}$. \\
Column Volume & $175 \mathrm{ml}$. \\
Volume ocupaded by adsorbent & $53 \mathrm{ml}$ \\
Density & 3.1 \\
Weight of adsorbent & $169.6 \mathrm{~g}$ \\
Volume of solution in the area occupied by the & $35 \mathrm{ml}$. \\
adsorbent. & cationic \\
Ion-Exchange class & $3.5,5.5,5.8$ \\
pH & $40.33 \mathrm{ml} / \mathrm{min} .=140 \mathrm{~mL} / \mathrm{H}$ \\
Wation Rate & $\approx 150,330 \mathrm{mg} / \mathrm{L}$
\end{tabular}

Table 2. Column and nanoadsorbents experimental conditions used in adsorption processes: Properties/features and Inorganic media.

\section{Results}

\subsection{Reaction mechanism on adsorbent}

The results showed that the introduction of $\mathrm{KOH}$ in molten potassium nitrate allows for different titanates as a function of the variation in the chemical composition of the melt. The probable mechanisms of the process that takes place in the investigated systems are represented in the figure 4 .

In this work were considered two ways in the formation of simple titanates ions:

1. The dissolution of $\mathrm{TiO}_{2}$ as a result of interaction with $\mathrm{OH}^{-}$ions.

2. The acid-base interaction of the Lux-Flood of $\mathrm{O}_{2}$-ions directly with $\mathrm{TiO}_{2}$ particles

The interaction between $\mathrm{TiO}_{2}+\mathrm{O}_{2}+\mathrm{K}$ ions promotes the formation of ions, which ones may not participate in the formation of $\mathrm{K}_{2} \mathrm{TiO}_{3}$ as product by high solubility in the melt and hydrolysis by water during washing of the sediments.

Structural fragments of the $\mathrm{TiO}_{2}$ network formed by interactions with $\mathrm{OH}-($ solution) can also be transformed into simple structural units titanate anion by the interaction of Lux-Flood $\left(\mathrm{TiO}_{2}+0^{2-}\right)$. This anion can participate in the formation of ions polytitanate $\left(\mathrm{K}_{2} \mathrm{Ti}_{n} \mathrm{O}_{2 n+1}+\mathrm{OH}-\right)$. The formation of titanates (polytitanates) of potassium can occur in hot melt but the rate of hydrolysis and decomposition of them is high so that the formation of potassium titanate crystal in the melt is of low probability.

Kinetic data obtained showed that the amount of potassium titanate formed by the molten salts treatment after the end of induction period (1 hour) does not depend of temperature or $\mathrm{KOH}$ content in the melt. 
This can consider this period of induction and the time needed to obtain the product system in thermodynamic equilibrium. The process of obtaining of this equilibrium system includes the processes indicated in Figure 4. Taking into account that the rate of these elementary processes is different, it is can say that the amount of product obtained is due to the ion content variation $\mathrm{O}^{2-}\left(\mathrm{KNO}_{3}\right)$ in the melt.

In the washing process, free positions of potassium cations in the crystal lattice may be occupied by cations of hydrogen during the washing process. Previous results indicate that the anionic structure of sintered polytitanate does not depend on potassium content. High rate of hydrolysis of simple potassium titanate by the washing allows obtain solids products in the form of potassium polytitanate formed as nanometric particles with molar relationships of $\mathrm{K}_{2} \mathrm{TiO} / \mathrm{TiO}_{2}=5.1$, at $500^{\circ} \mathrm{C}$ of temperature.

In the cooling stage, it is possible that the formation of crystalline titanates includes both titanium compounds: oxides and titanates and then the generation of different forms of $\mathrm{TiO}_{2}$ as: anatase, brookite, and rutile and one part of titanium oxide crystals was formed by interactions between anions of titanate.

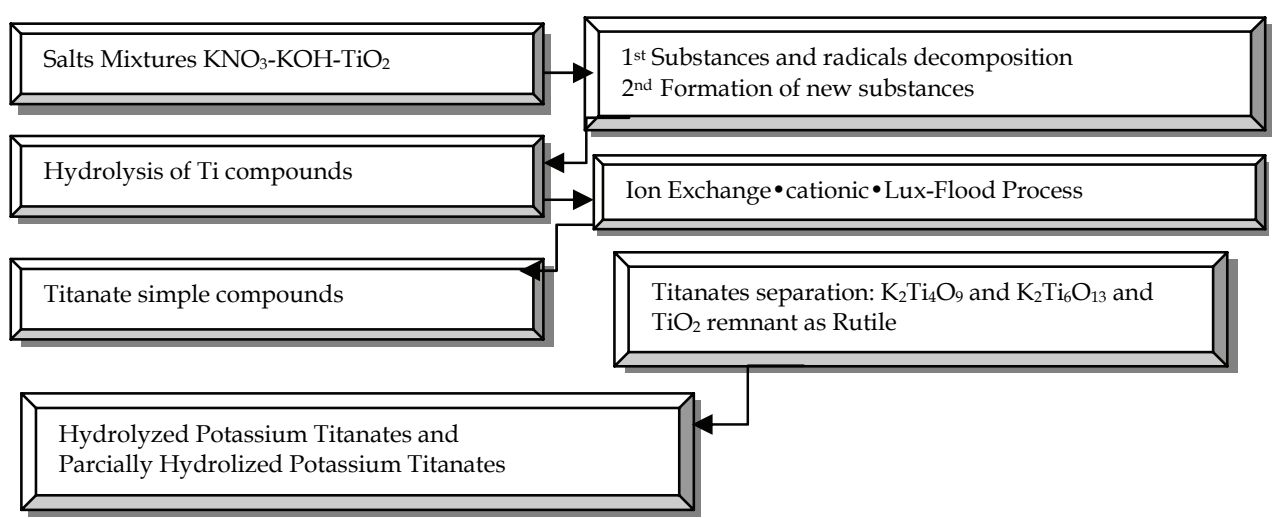

Fig. 4. Chemical processes scheme in systems treated by the $\mathrm{KNO}_{3}-\mathrm{KOH}-\mathrm{TiO}_{2}$ molten salts processes.

\subsubsection{Adsorption dynamic test}

Before performing adsorption column, it is necessary to determine the coefficients of adsorption in static systems, for lead present in the different waters, with the aim of designing appropriate operating conditions.

In addition adsorption results have determined that it is possible to perform adsorption studies by column experiments under real conditions of flow (non-equilibrium situation).

Chemical analysis data (Figure 5.) showed than the adsorbent effectively removal $\mathrm{Pb}^{2+}$ ions in the solution with $\mathrm{pH}_{0}=5.5$. After passing the solution 1 through the adsorption column, the lead concentration decreased to $0.5-0.6 \mathrm{mg} / \mathrm{dm}^{3}$, meeting the requirements of national rules for river water $\left(1.0 \mathrm{mg} / \mathrm{dm}^{3}\right)$. The best lead removal of $\mathrm{Pb}^{2+}$ was observed after three hours of contact, and then the saturation time did not influence the effectiveness of the removal of lead is shown in Figure 4. However, for solution $2\left(\mathrm{pH}_{0}=3.5\right)$, the remaining concentration of $\mathrm{Pb}^{2+}$ was relatively higher but decreased to $14-23 \mathrm{mg} / \mathrm{dm}^{3}$. 


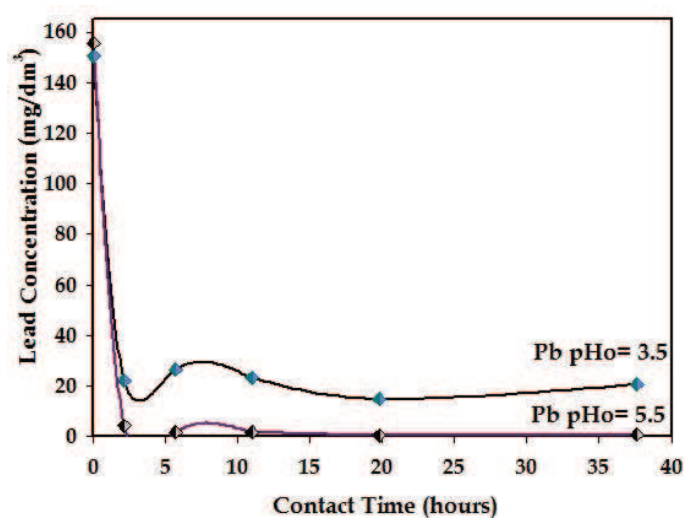

Fig. 5. Effect of contact time on the content of $\mathrm{Pb}$ in the passed aqueous solution prepared at $\mathrm{pH}$ of 3.5 and 5.5 .

During adsorption process, both eluted (purified) solutions showed a high content of K, whose concentration changed during the time of saturation of the adsorbent (Figure 6.). During first ten hours, the content of K increased from 0.07 to $118 \mathrm{mg} / \mathrm{dm}^{3}$ (solution 1) and $205 \mathrm{mg} / \mathrm{dm}^{3}$ (solution 2) and then decreased between 86 and $93 \mathrm{mg} / \mathrm{dm} 3\left(\mathrm{pH}_{0}=5.6\right)$ and between 133 and $143 \mathrm{mg} / \mathrm{dm}^{3}\left(\mathrm{pH}_{0}=3.5\right)$.

Potassium concentration in the eluted solution was higher for the solution 1 than those in solution 2, which can be explained by the presence of two parallel processes of ion exchange:(1) $\mathrm{Pb}^{2+} \leftrightarrow 2 \mathrm{~K}+\left(\mathrm{PbOH}^{+} \leftrightarrow \mathrm{K}^{+}\right)$and (2) $\mathrm{H}^{+} \leftrightarrow \mathrm{K}^{+}$, by reducing the $\mathrm{pH}$, second process rate increases strongly, dominating the first. With increasing $\mathrm{K}$ content increased the $\mathrm{pH}$ value of the eluted solution to 10.6 (solution 1) to 11.3 (solution 2), (Figure 6). It is noteworthy that the maximum value of $\mathrm{pH}$ was observed in the first sample collected and gradually decreased (solution 1) or stabilized (solution 2). The elution rate retained its original value during 15 hours of contact under conditions of constant hydrostatic pressure, and then gradually decreased from 140 to $100 \mathrm{~cm}^{3} / \mathrm{h}$ (38 contact hours) is shown in Figure 7.

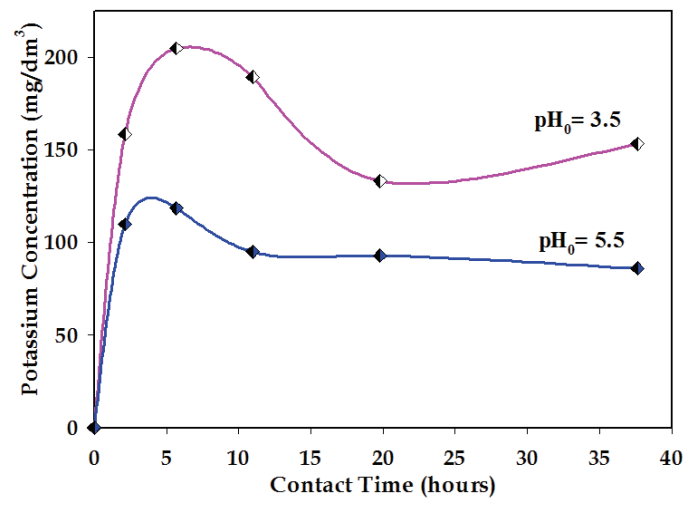

Fig. 6. Effect of contact time on the content of $\mathrm{K}$ in the passed aqueous solution prepared at $\mathrm{pH}$ of 3.5 and 5.5 . 


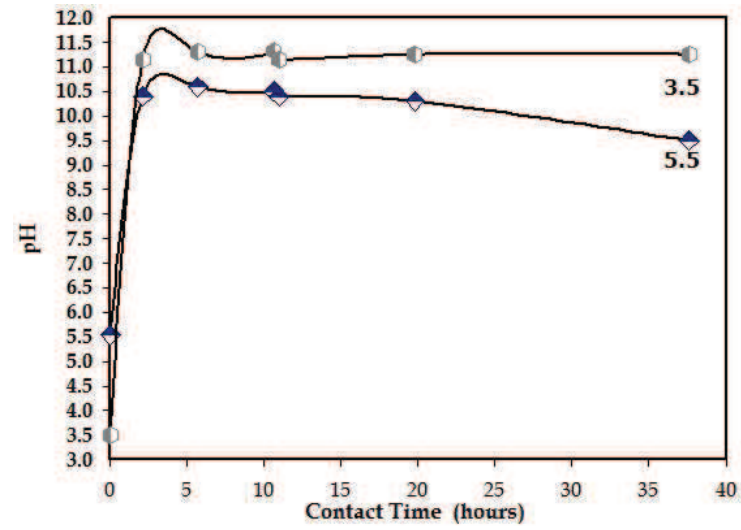

Fig. 7. Effect of contact time vs $\mathrm{Ph}$ in adsorption process with potassium polytitanates.

The behavior of $\mathrm{pH}$ in solutions with $\mathrm{Pb}$, has shown that in solution with $\mathrm{pH}_{0}=3.5$ were obtained higher values after the first hour of sampling compared with those in which ones carried out with $\mathrm{pH}_{0}$ 5.5. This may be due to adsorption capacity lower in solutions with lower $\mathrm{pH}_{0}$ to 5.5 inducing the formation of more precipitation of hydroxide-like compounds in the initial stage of the experiment and therefore a lower activity between the adsorbent surface interactions and lead ions in solution.

Figure 9 shows a comparison in measuring the $\mathrm{pH}$ of the dynamic experiments carried out at this stage lead.

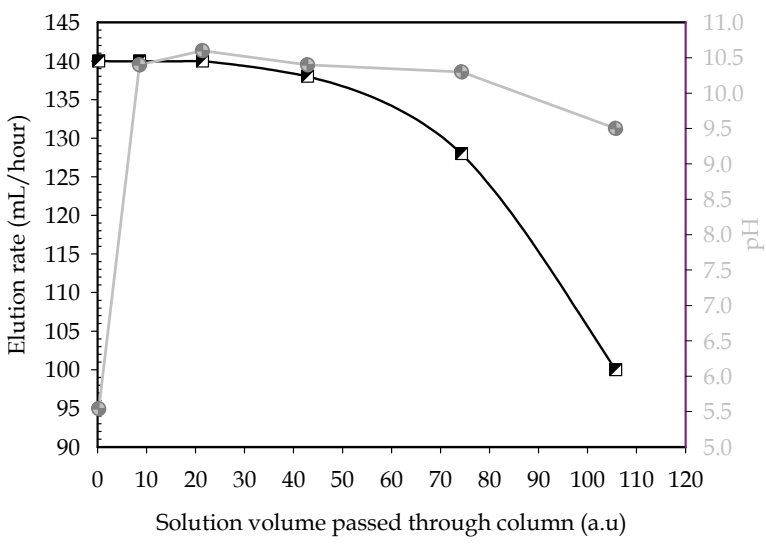

Fig. 8. Influence of solution volume passed through column versus elution rate of $\mathrm{Pb}$ solution and versus $\mathrm{pH}$. The experiments were done on a $\mathrm{pH}_{0}=5.5$. The initial concentration was: $\mathrm{Pb}=150.55, \mathrm{~K}=.065 \mathrm{in} \mathrm{mg} / \mathrm{L}$.

Figure 8 shows a graph of the volume passed through the column vs. elution rate and versus $\mathrm{pH}$. In the figure 9 it can be seen that the elution rate on dynamic adsorption experiments of $\mathrm{Pb} 150 \mathrm{mg} / \mathrm{L}$ remains constant during the first stage almost as much as $50 \%$ of the passage of total solution volume, the rate decreases in the last quarter of the experiment, this may be due to saturation of available adsorption sites on the adsorbent. 


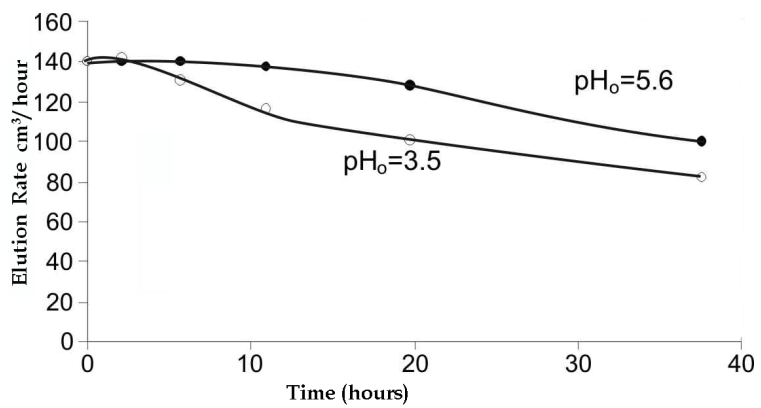

Fig. 9. Effect of contact time on the flow rate of aqueous solution.

\subsection{XRD for nanoadsorbents synthesized}

The goal of the XRD studies in this research was indentify crystalline phases, also chemical composition of materials applied in the different stages of processing. Studies were first realized in the start materials. The quantify of crystalline phases was made in previous studies by Li et al, 1999 .

Figure 7 shows $X$-ray diffraction pattern corresponding to the obtained samples in the method of making of potassium polytitanates nanoadsorbents by means of precursors route in molten salts. Details of synthesis for each material is given and described in the experimental methodology of this research. Chart 74-0275 was identified as $\mathrm{K}_{2} \mathrm{Ti}_{6} \mathrm{O}_{13}$ of ICDD database.

Crystalline phases contents in selected composition as optimum have shown quasicrystalline behavior for a $\mathrm{N}$ value $\left(\mathrm{K}_{2} \mathrm{O} / \mathrm{TiO}_{2}\right)$ of 5.1 . Whit this relationship the main XRD diffraction intensities obtained in $2 \theta$ degrees were: 11.2, 23.9, 29.8, 33.1, 34.7, 37.8, 43.1, 47.5, $47.7,51.9,55.1,57.3,58.7,59.2,61.9$ y $66.4^{\circ}$ (main reflexions in volume) these results are in agreement with Liu et al 2005.

Besides it is very important to note than potassium titanates pure compounds as: $\mathrm{K}_{2} \mathrm{Ti}_{2} \mathrm{O}_{5}$ (potassium dititanate), $\mathrm{K}_{2} \mathrm{Ti}_{4} \mathrm{O}_{9}$ (potassium tetratitanate) and $\mathrm{K}_{2} \mathrm{Ti}_{6} \mathrm{O}_{13}$ (potassium hexatitanate) all of them includes closed reflections in 2 teta degrees scale. Figure 11 shows a graph corresponding to potassium titanates in form of pure compounds.

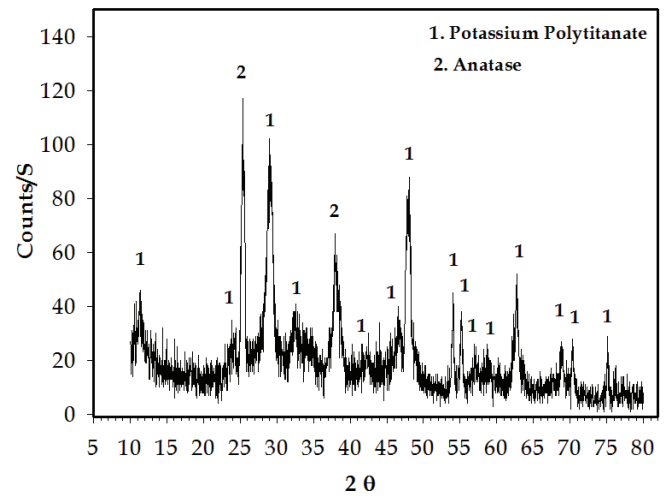

Fig. 10. X-ray diffraction (XRD) patterns of potassium polytitanates nanoadsorbents from samples prepared by molten salts synthesis, , with relationship of $\mathrm{TiO}_{2} / \mathrm{K}_{2} \mathrm{O}=5.1$. 


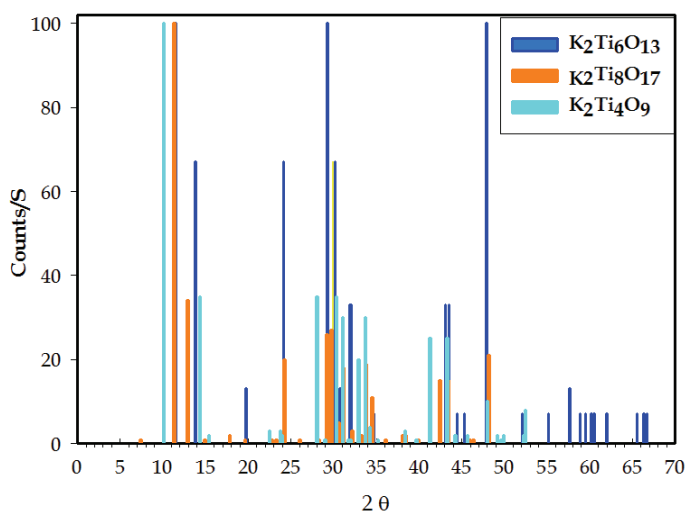

Fig. 11. X-ray diffraction (XRD) patterns from pure potassium titanate: $\mathrm{K}_{2} \mathrm{Ti}_{4} \mathrm{O}_{9}, \mathrm{~K}_{2} \mathrm{Ti}_{6} \mathrm{O}_{13} \mathrm{y}$ $\mathrm{K}_{2} \mathrm{Ti}_{8} \mathrm{O}_{17}$.

According to EDX-S analysis results the crystalline phases of the material produced from mixtures of PTP containing oxides of titanium as $\mathrm{K}_{2} \mathrm{Ti}_{6} 0_{13}$.

Figure 12 shows atomic arrangements obtained from the data of X-ray diffraction for nanoadsorbents designed in powder cell program software.
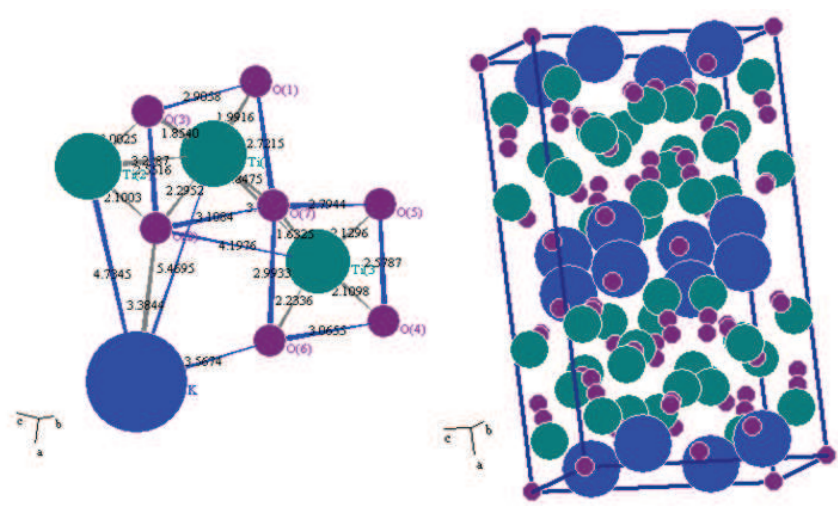

Fig. 12. Atomic arrangements obtained with nanosorbents data, nanostructure was modeled by Powder Cell Software and ICDD 2004 data base.

\subsection{Surface area measurements \\ 3.3.1 Textural properties}

There exist three parameters used in the measurement of porosity: specific surface area, the specific pore volume (open porosity) and size and distribution pore. Results show values of surface area were similar than those obtained by Wallenberg et al.,1990 from potassium tetratitanate of $13.9 \mathrm{~m}^{2} / \mathrm{g}$, in potassium polytitanates nanoadsorbents was obtained $13.96 \mathrm{~m}^{2} / \mathrm{g}$ as result from without treatment samples

In order to know the surface characteristics of both external and internal, in the adsorbents, there was an isotherm nitrogen adsorption on a sample of granular adsorbent with BET technique, the method for sample preparation described previously in experimental part. 
The nitrogen adsorption isotherm obtained of the based in potassium polytitanates, is presented in figure 13. BET measurements were realized for three sections of column: top, middle and bottom, also one sample without adsorption. Such plots are typical for microporous solids with a significant contribution to the meso and macroporous scale (Ruthven, 1884). The higher value was presented in the sample corresponding to top of column of $2.54 \mathrm{~m}^{2} / \mathrm{g}$. Figure 13

In the nanoadsorbent particles analyzed (sample without treatment), were found in the dimensions range from 100 to 150 microns. Results (shape of the isotherm) have indicated that the porosity detected, corresponding to type mesoporous adsorbents with regions of porosity of relative pressures ( $\mathrm{P} / \mathrm{Po}) 0$ to 0.2 , then from 0.2 to 0.32 on the scale corresponds to the inter-lamellar distances that exist in the structure of the potassium titanates. The results showed that there is a pore size distribution variation, containing a scale small fraction less than $50 \mathrm{~A}^{\circ}$ assessed by TEM.

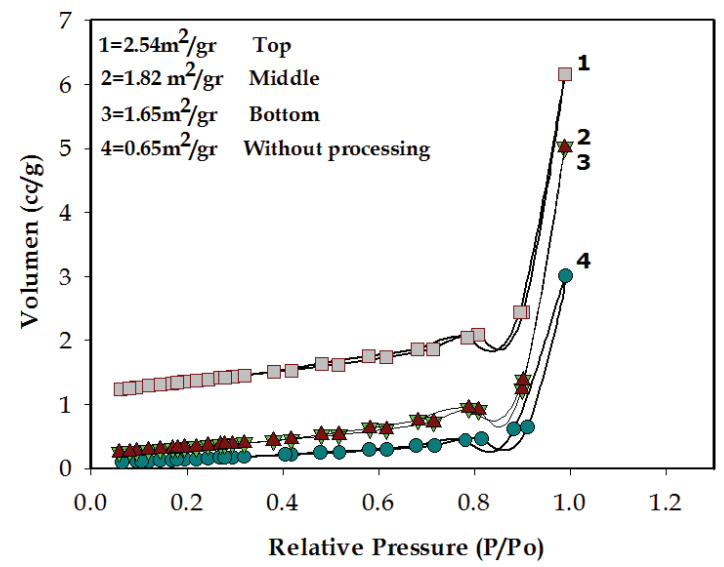

Fig. 13. Results of specific surface area measurement of dynamic experiments for samples with $\mathrm{Pb}: 1$ ) granular adsorbents agglomerated with potato starch, without adsorption proceses, 2), 3) and 4) same adsorbents extracted from the adsorption column with solutions of $\mathrm{Pb}$, on the top, middle and bottom, respectively

\subsection{SEM Images}

The morphologies of the start material samples were investigated by scanning electron microscopy. Figure 14 shows the SEM images of quasicristalline potassium polytititanate nanoadsorbent. From figure 2a, was found that the this material consisted of agglomerates of well-defined layers with sizes of 100 to $500 \mathrm{~nm}$. The surfaces of these layers were relatively smooth. After crystallization, the sizes of these layers kept unchanged. However, their surfaces became rough (Figure 17). Obviously, the layers of quasicrystalline K2Ti4O9 were composed of small agglomerates primary particles of several nanometers in size.

Figure 15 shows a $10000 \mathrm{X}$ photomicrograph of a sample of adsorbent after the adsorption process of lead. Samples have remained for a contact time of one hour with the solution corresponding to the concentration of $155 \mathrm{mg} / \mathrm{L} \mathrm{of} \mathrm{Pb}\left(\mathrm{NO}_{3}\right)_{2}$. They can be observed with the morphology of agglomerates of lead adsorbed on the surface of potassium polytitanates. 


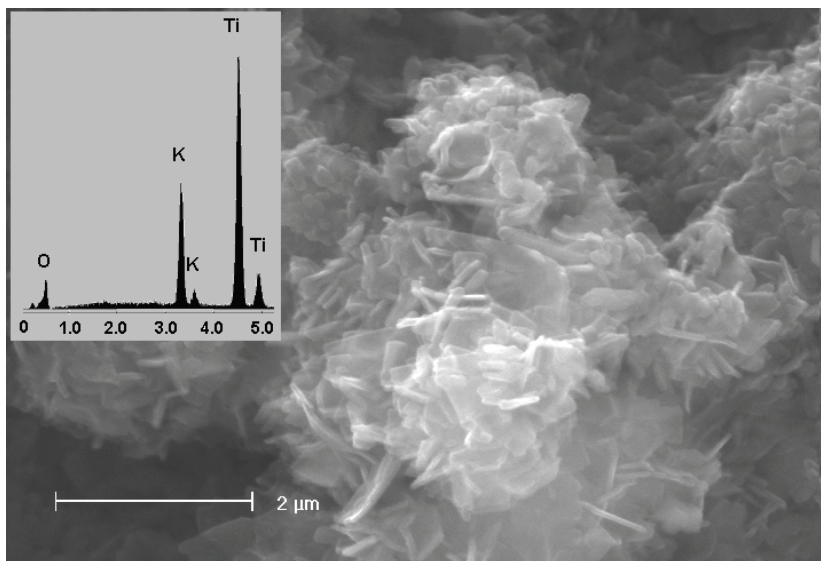

Fig. 14. SEM Photomicrography. Agglomerates of potassium polytitanates nanoadsorbents a) y b) spectrum obtained by SEM-EDXS Technique.

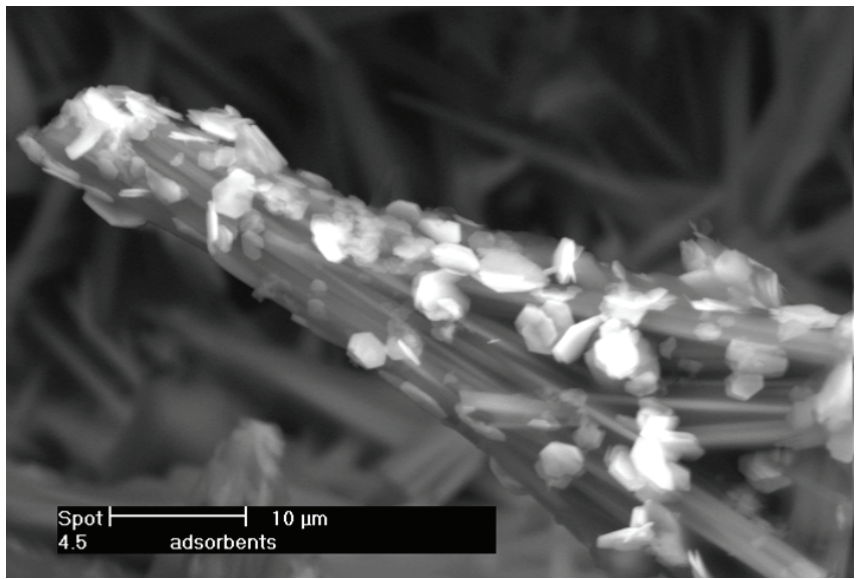

Fig. 15. Photomicrography of nanoadsorbents in lead adsorption. The concentration of solution was $155 \mathrm{mg} / \mathrm{L}$ of solution. The contact time corresponded to one hour.

\subsection{Thermal analysis of nanoadsorbents of potassium polytitanates}

Thermal analysis data of Figure 16, corresponding to PTP have indicated that the obtained material contained adsorbed water (removed from 350 to $550{ }^{\circ} \mathrm{C}$ ) and structural water (removed from 500 to $700^{\circ} \mathrm{C}$ ). The thermogram ATG showed a partial loss of sample weight during their analysis of $8.8 \%(\mathrm{wt} \%)$ at $555^{\circ} \mathrm{C}$, subsequently detected a loss of 4.7 $(\mathrm{wt} \%)$ to $714^{\circ} \mathrm{C}$ generated by the decomposition of groups $\mathrm{Ti}-\mathrm{OH}$ (Shimizu et al., 1981) (removal of structural water).

The DTA thermogram indicated the presence of an exothermic reaction to $703^{\circ} \mathrm{C}$, which corresponds to the onset of crystallization of the PTP (Bergon et al., 1984). At a temperature of $1030^{\circ} \mathrm{C}$, there is only the transformation of anatase and rutile $\mathrm{TiO}_{2}$. 


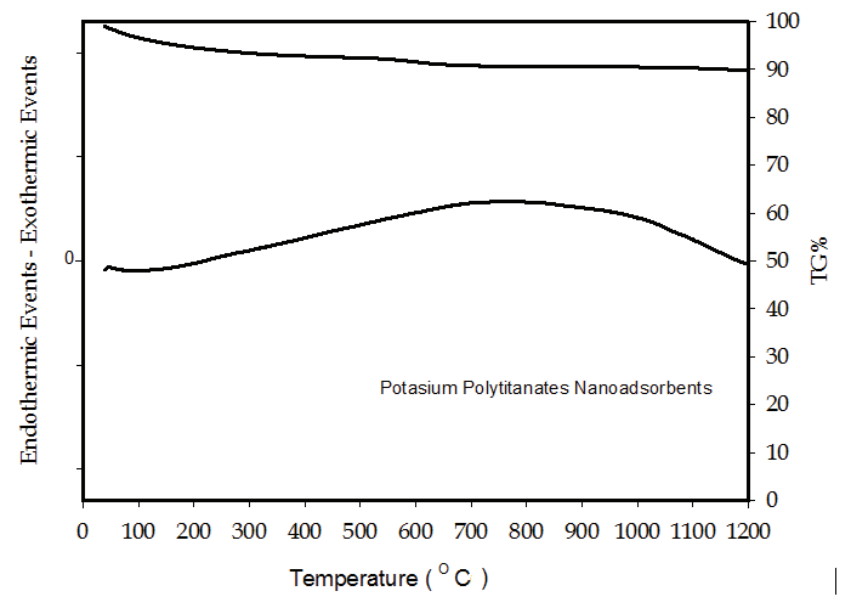

Fig. 16. Thermal analysis of Potassium polytitanates nanoadsorbents.

\subsection{Transmission Electronic Microscopy (TEM)}

Morphology of the nanaoadsorbents was further investigated by transmission electron microscopy. Figure 17 shows the TEM image of quasi-crystalline $\mathrm{K}_{2} \mathrm{Ti}_{4} \mathrm{O}_{9}$ (layers) and $\mathrm{K}_{2} \mathrm{Ti}_{6} \mathrm{O}_{13}$ (fibers). It was found that some well-defined lamellar agglomerates of about $100 \mathrm{~nm}$ in sizes were connected to each other to form pores in the range of 30 to $50 \mathrm{~nm}$. During the sonication for TEM measurement, some small primary particles were dropped from the fibers of $\mathrm{K}_{2} \mathrm{Ti}_{6} \mathrm{O}_{13}$. These monodispersed primary particles are of about lower than $50 \mathrm{~nm}$ in size, in agreement with SEM observation. Most of the morphology of the particles in PPN was still preserved well after sonication. These secondary agglomerates are slightly larger than those of anatase phase. Mesopores formed among the small interlayer spaces in nanoadsorbents, while macropores or large mesopores produced among of PPN were also observed. This confirms the existence of a hierarchical porous structure in the nanoadsorbents. The TEM image of this is consistent with the XRD and SEM results obtained.

\subsection{Infrared spectroscopy of samples after and before of the adsorption processes}

The IR analysis confirms that there is no generation of new functional groups at the end of the adsorption process. When comparing the spectrums of figure 18, are very similar, there is only a small variation in the intensity of some small peaks located around 1440 and 1750 $\mathrm{WLcm}^{-1}$, these peaks can be attributed to ion exchange occurred between ions of $\mathrm{K}^{+}$and $\mathrm{Pb}^{2+}$ during the adsorption process. Nakamoto et al, 1978.

The adsorption promotes a decrease in the intensity of the absorption bands of 1448 and 1613 cm.-1 (angular vibration groups Ti-OH and $\mathrm{HOH}$ ). This indicates that the incorporation of $\mathrm{Pb}^{2+}$ in the surface structure of titanate decreases the concentration of $\mathrm{Ti}-\mathrm{OH}$ groups and adsorption of $\mathrm{H}_{2} \mathrm{O}$ in the air. While, there is a variety of characteristics of Ti-O bonds in the octahedral $\mathrm{TiO}_{6}$, instead of an adsorption peak at $500 \mathrm{~nm}$ where two peaks at 500 and $650 \mathrm{~nm}$. 


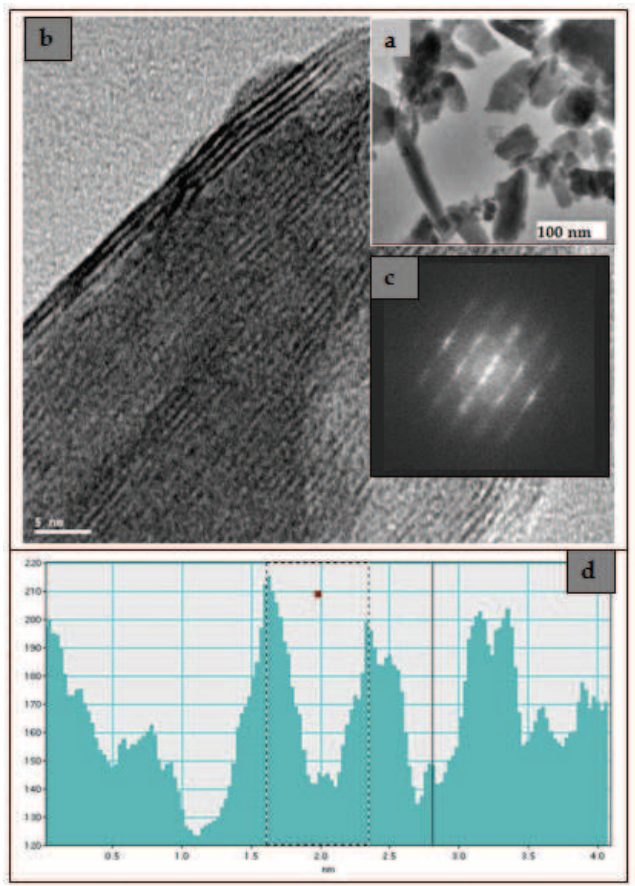

Fig. 17. TEM images of scratched nanoadsorbents: a) TEM image of a nanoadsorbents composed of several lamellae, b) scratched surface morphology (c) SAED pattern of this whisker showing the same crystallographic orientation of lamellae and d) interlayer spacing on potassium polytitanates structure.

\subsection{Solubility in nanoadsorbents, saturated, press and heat treated}

After the adsorption experiments samples were milled, mixed, heat treated $\left(780\right.$ and $\left.900^{\circ} \mathrm{C}\right)$ and afterward poured into glass flasks, in a $10 \% \mathrm{v} / \mathrm{v}$ of adsorbent with the rest of water. These solutions were heat treated of $96^{\circ} \mathrm{C}$ during a period of 5 hours (Japanese rule JISR3520 and Russian rule GOST 10134-82). The finality of these processing was the assess of the final lead content and consider as free in solution and its total solubility. Results (Table 3) have shown, that final content in the samples were treated to $900^{\circ} \mathrm{C}$ has met with a lower level for water for human consume(Abalak et al, 2003).

Heat treatment Samples Lead Concentration $(\mathrm{mg} / \mathrm{L})$

\begin{tabular}{c|c}
$780^{\circ} \mathrm{C}$ & $\mathbf{0 . 1 4 0}$ \\
\cline { 2 - 2 } $900^{\circ} \mathrm{C}$ & $\mathbf{0 . 0 6 4}$
\end{tabular}

Table 3. Results of chemical analysis by ICP technique for nanoadsorbents heat treated samples to 780 and $900^{\circ} \mathrm{C}$. 


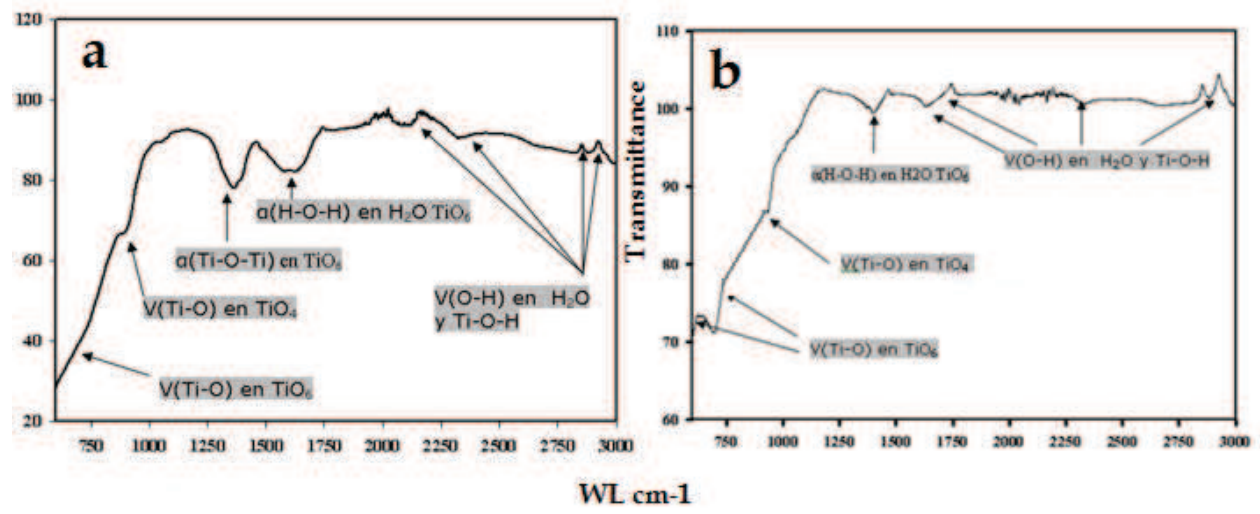

Fig. 18. IR spectrums for two samples a) without adsorption process and b) adsorbed with lead ions.

In this study was developed a new adsorbent for the removal of divalent cations on metal oxides, which allows continuity between surface reactions and precipitation. The model applied in Figura 19 fits the model of surface complexity, whereas the precipitation in the solid is described by the formation of a solid solution whose composition varies continuously between that of the original material and a pure precipitate cationic adsorption. It demonstrated the ability of the surface precipitation model to describe the adsorption equilibrium of metal cations in potassium hydroxide amorphous. The model can also be extended to describe competitive cationic and anionic adsorption.

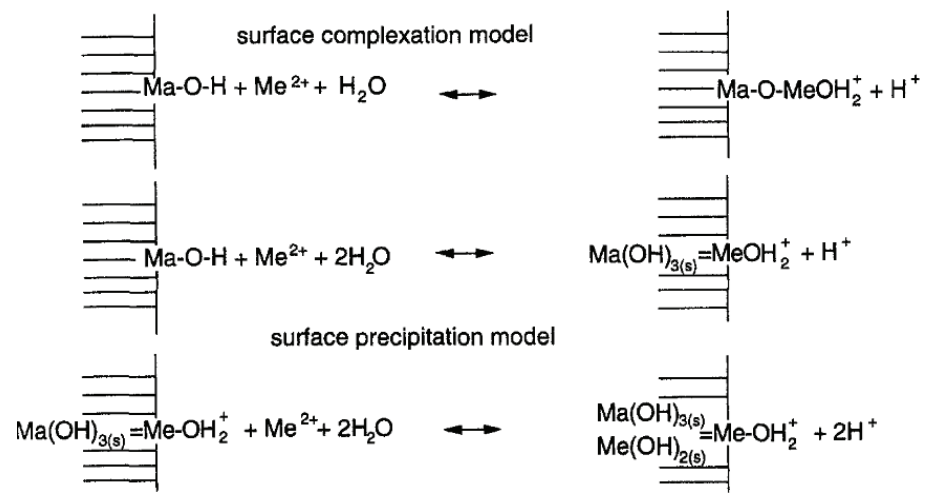

Fig. 19. Scheme of surface complexation/precipitation reactions. Modified from Lützenkirchen J. \& Behra, Ph (1981) of the original model of Farley et al. (1996).

Farley et al, 1984 proposed surface precipitation model in order to cations adsorption in metallic oxides.

Our working group will shortly present a study on the transformation of potassium titanate about this nanoadsorbents kind being that it is possible carry out after the adsorption process a treatment to convert an orthorhombic structure(potassium titanate) in a new metallic titanate(metallic titanate) with new functional properties. 


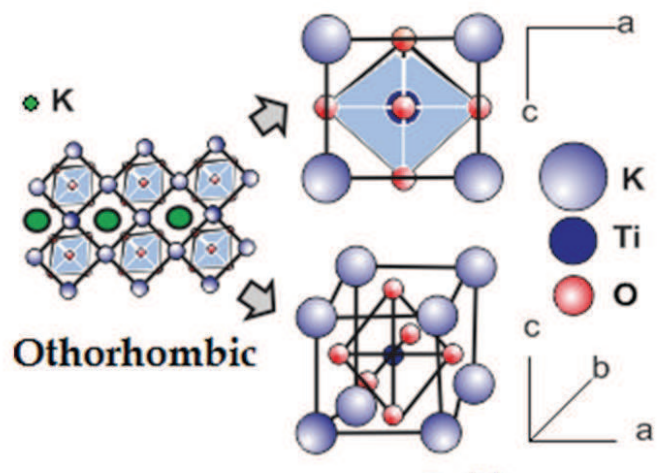

Cubic

Fig. 20. Structural transformation of the nanoadsorbents with help of heat treatment.

The results confirmed that the nanoadsorbents based on potassium polytitanates promoted the removal of lead ions from aqueous solutions. The greatest efficiency of removal was obtained in the No.1 solution, slightly acidic $\left(\mathrm{pH}_{0}\right.$ 5.6). To explain the action of the investigated nanoadsorbents, it is to consider the mechanism of interaction between potassium titanates and $\mathrm{Pb}$-containing solutions with different $\mathrm{pH}$. It is well known that the chemical speciation of $\mathrm{Pb}$ in aqueous solutions depends on the $\mathrm{pH}$ (Dean et al. 1972). In acidic solutions $(\mathrm{pH}<5) \mathrm{Pb}^{2+}$ ions predominate, for $\mathrm{pH}$ values in the range from 5 and up to 6 , the solutions have a high ion content $\mathrm{PbOH}^{+}$, and also $\mathrm{Pb}^{2+}$. In solutions with $\mathrm{pH}>6$ is favored precipitation of $\mathrm{Pb}(\mathrm{OH})_{2}$. The investigated adsorbent has a hydrolysis high rate and becomes to its hydrated form (Zheng et al., 1998, Nunes et al., 2006), thus increasing the pH and the concentration of $\mathrm{K}^{+}$ions in aqueous solution. In the first stage of interaction of the adsorbent with the solution of lead salts, can be seen two parallel processes: the adsorption of $\mathrm{Pb}^{2+}$ and $\mathrm{PbOH}^{+}$ions on the inner surface of the potassium titanates crystals as well as the hydrolysis of titanate potassium. After adsorption of $\mathrm{Pb}^{2+}$ ions, they are involved in a process of ion exchange with $\mathrm{K}^{+}$cations, which are located between channels from the crystals of the adsorbent (Figure 1 ). Our results can be applied perfectly to Farley model et, al 1996.

The most important aspect in this work is that it is possible to obtain new materials from contaminated materials using a single heat treatment and without human health risks.

\section{Conclusions}

In this work were developed potassium polytitanates nanoadsorbents by molten salt synthesis with general formula $\left(\mathrm{K}_{2} \mathrm{Ti}_{n} \mathrm{O}_{2 n+1}\right)$, where the relationship $\left(\mathrm{K}_{2} \mathrm{O} / \mathrm{TiO}_{2}\right)=5.1$, with a homogeneous structure and high functional properties. Nanoadsorbents obtained with a lamellar and fibrous structure, have shown a high intercalation of cations, ion exchange activity and structure layer, and fibrous, characterized by high adsorption properties.

Nanoadsorbents were obtained as ceramic materials whit porosity and quasi-crystalline phases regulated. They serve for the immobilization of $\mathrm{Pb}^{2}+$ and with an additional heat treatment can be obtained ceramics general interest. 
The lead removal mechanisms in the adsorbent produced in granular form and applied to adsorption columns, was carried out by a combination of ion exchange-adsorptioncoprecipitation of $\mathrm{Pb}^{2+}$. During the continuous contact time, nanoadsorbents structure was deteriorated, slowing the elution rate, but this did not influence in the effectiveness of metallic removal.

The intra-particular $\mathrm{Pb}^{2+}$ diffusion into adsorbent, has occurred in 2 stages: 1) while the metal ions, rapidly diffuse between particles of the nanoadsorbents, at the beginning of adsorption and 2) when the intra-particular diffusion is reduced and then stabilized. The kinetics of adsorption depends of: metal ions concentration in solution, adsorbent dose, $\mathrm{pH}$ and contact time, and does not depend on the particle size of adsorbent.

In the sintering is transformed species generating titanate $\mathrm{Pb}$ metal. $\left(\mathrm{PbTiO}_{3}\right)$. One possible application can be as electronic sensors and piezoelectric devices.

Polytitanates potassium consisted of particles agglomerate like-flake shape with a nominal diameter of 50-300 nm and a thickness of 20-60 nm, which in turn have a lamellar structure, the space between the plates, which forms nanopores. When heating the particles to a temperature of potassium polytitanates $500^{\circ} \mathrm{C}$, they crystallize to nanowiskers.

The chosen methodology has included in the study of the effect of synthesis parameters on the physico-chemical and adsorption properties of potassium polytitanates and optimization of the properties of nanomaterials for use as a highly effective adsorbent for bivalents cations.

Studies identified the optimal synthesis regimes of potassium polytitanates (weight ratio of raw materials $\mathrm{TiO}_{2}: \mathrm{KOH}: \mathrm{KNO}_{3}=1: 1: 32$; at $500{ }^{\circ} \mathrm{C}$ of temperature, time $1 \mathrm{~h}$ ) and its further processing (sequentially washed with water and $0.1 \mathrm{~N}$ aqueous solution of hydrochloric acid, drying, milling. In potassium polytitanates, always get ultrafine materials (the average size of agglomerates of nanoparticles of hydrated potassium polytitanates of 1.4 microns.

The structure and composition of Potassium Polytitanates studied by Xray diffraction analysis (Fig. 10), infrared spectroscopy and scanning electron microscopy (Fig. 18). IRS show slight differences in the adsorbed samples, data no revels differences among the obtained samples. According XRD data base ICDD 2004 shows that the composition of phase is variable and its depends of the reagents relationship, the selected technology and the synthesis temperature conditions. Its means that in the stage of synthesis is very important to have a PPN with low content of impurities as $\mathrm{K}_{2} \mathrm{Ti}_{4} \mathrm{O}_{9} \mathrm{~K}_{2} \mathrm{Ti}_{6} \mathrm{O}_{13}$, the product structure will depends largely of the synthesis temperature and their process of purification(washes).

\section{Acknowledgment}

Author thanks the financial support of Consejo Nacional de Ciencia y Tecnología (CONACYT, México), through the project SEP-CONACYT-2006 No 54883 and the scholarship given to M.A. Aguilar-González (No. 201784).

\section{References}

Afanasiev, P. (2006) Molten Salts Synthesis of Alkali Metal Titanates. J. Mater. Sci. Vol. 41 p.p 1187-1195.

Albalak, R. Noonan, G. Buchanan, S. Flanders, W.D. Gotway-Crawford, C. Kim, D. Jones, R.L. Sulaiman, R. Blumenthal, W, Tan, R. Curtis, G. \& McGeehin, M.A. (2003). Blood 
lead levels and risk factors for lead poisoning among children in Jakarta, Indonesia. The Science of the Total Environment Vol.301 p.p 75-85

Anthony, R.M. \& Breimburst, L.H. (1981).Determining Maximum Influent Concentrations of Priority Pollutants for Treatment Plants. Journal of the Water Pollution Control Federation. Vol. 53, No 10, p.p 1457-1468.

Ayyappan, R., Carmalin-Sophia, A., Swaminathanb, K., \& Sandhya S. (2005). Removal of $\mathrm{Pb}$ (II) from aqueous solution using carbon derived from agricultural wastes. Proc. Biochem. Vol. 40, p.p 1293-1299.

Constantino, V.R.L. Barbosa, C.A.S. Bizeto, M.A. \& Dias P.M (2000). Intercalation Compounds involving Inorganic Layered Structures. Anais da Academia Brasileira de Ciências. Vol. $72(1)$.

Bansal, V. Poddar, P. Ahmad, A. \& Sastry, M. (2006).Room-Temperature Biosynthesis of Ferroelectric Barium Titanate Nanoparticles, J. Am. Chem. Soc., Vol.128 No.36, pp 11958-11963.

Bavykin, D.V. Friedrich, J.M. \& Walsh, F.C. (2006) Review: Protonated Titanates and $\mathrm{TiO}_{2}$ Nanostructured Materials: Synthesis, Properties, and Applications. Advanced Materials, Vol. 18. p.p 2807-2824. WILEY-VCH Verlag GmbH \& Co. KGaA, Weinheim.

Bavykin, D.V. \& Walsh, F.C. (2009). Elongated Titanate Nanostructures and Their Applications. Eur. J. Inorg. Chem., 977-997 @ 2009 Wiley-VCH Verlag GmbH \& Co. KGaA, Weinheim3.2.1. Fuel Cells and Batteries.

Barrier, R.M. (1978) Zeolites and Clay Minerals, Academic Press, London.

Bergon, C., y Risbud, S. (1984). The One-Component System, The titania and zirconia systems In:Introduction to phase equilibrium in ceramic the Amerincan Ceramics Society. Urbana, illinois. p.p 9-19.

Dean, J.G. Bosqui, F.L. \& Lanouette, K.H. (1972). Removal of heavy metals from waste-water. Env. Sci. Tech. 6, 518-524.

Fox M. A. \& Dulay M. T. (1993). Heterogeneous Photocatalysis. Chem. Rev., 93, 341-357.

Grätzel, M. (2001). Photoelectrochemical cells. Nature. Vol. 414, p.p 338-344.

Gregorová, E., y Pabst, W. 2007. Porosity and Pore Size Control in Starch Consolidation Casting of Oxide Ceramics-Achievements and Problems, J. Eur. Ceram. Soc. Vol. 27 p.p 669-672.

Hayashi, H. \& Hakuta, Y. (2010) Review: Hydrothermal Synthesis of Metal Oxide Nanoparticles in Supercritical Water Materials, Open Access. Vol.3, p.p 3794-3817; doi:10.3390/ma3073794 ISSN 1996-1944 www.mdpi.com/journal/materials.

Hrudey, S.E. Chen. W \& Rosseaux, C.G (1995) Bioavailability in environmental risk assessment. Lewis Publ., Boca Raton, FL.

Klein, M. (1985). Filtering device for treating contaminated aqueous solutions. US patent 4505823. $11 \mathrm{pp}$.

Ion, A.C. Ion, I. and \& Culetu, A. (2010). Lead adsorption onto exfoliated graphitic nanoplatelets in aqueous solutions. Materials ScienceandEngineeringB. Article in press.

Li, Y. Gao, X.P. Li, G.R. \& Pan, G.L. Yan, T.Y. \& Zhu, H.Y.(2009). Titanate Nanofiber Reactivity: Fabrication of $\mathrm{MTiO}_{3}(\mathrm{M}) \mathrm{Ca}, \mathrm{Sr}$, and Ba) Perovskite Oxides. J. Phys. Chem. C 2009, 113, 4386-4394.

Lanphear, B.P. Hornung, R. Ho, M. Howard, C.R. Eberly, S. \& Knauf, K. Environmental lead exposure during early childhood. J Pediatr. 2002 Jan;140(1):40-7. General and 
Community Pediatrics Department, Children's Hospital Medical Center, Cincinnati, OH 45229, USA.

Laurentin, A. Cardenas, M. Ruales, J. Pérez, E. \& Tovar, J. (2003). Preparation of indigestible pyrodextrins from diferent starch sources, J. Agric. Food Chem, 51, 18, p.p 5510-5515.

Li, G.L. Wang, G.H. \& Hong, J.M.(1999). Synthesis of $\mathrm{K}_{2} \mathrm{Ti}_{6} \mathrm{O}_{13}$ whiskers by the method of calcination of $\mathrm{KF}$ and $\mathrm{TiO}_{2}$ mixtures. Materials Research Bulletin, Vol. 34, Nos. 14/15, pp. 2341-2349.

Luckchis, G. M (1973) Chem. Eng. Vol. 80:p.p 111.

Lützerkitchen, J.\&. Behra, Ph. (1996). On the surface precipitation model for cation sorption at the (Hydr)oxide Water Interface. Kluwer Academic Publishers. Printed in the Netherlands. Aquatic Geochemistry Vol.1: p.p 375-397

Matsumiya, H.), Masai, H.), Terazono, Y.), Iki, N.) \& Miyano S. (2003). Chelating adsorbent for heavy metal ions prepared by loading anion-exchange resin with thiacalix[4]arenetetrasulfonate. Bulletin of the chemical society of Japan Vol. 76, No. 1 p.p.133-136

Naicker, N. Norris, S. Mathee, A. von Schirnding, Y. \& Richter, L. (2010). Prenatal and adolescent blood lead levels in South Africa: Child, maternal and household risk factors in the Birth to Twenty cohort. Environmental Research Vol. 110 p.p 355-362. Nakamoto, K. (1978). Infrared and Raman Spectra of Inorganic and Coordination Compounds, John Wiley and Sons, New York.

Noonan, G. Albalak, R. Buchanan, S. Flanders, W.D. Gotway-Crawford, C. Kim, D. Jones R.L. Sulaiman, R. Blumenthal, W. Tan, R. Curtis, G. McGeehin, M.A. McElroy, R. Schurz-Rogers, R. Randolph, W. Rubin, C. \& Jarrett J.( March 2001). Blood lead levels and risk factors for lead poisoning among children, Torreon, Coahuila, Mexico. Final Report. Lead Poisoning Prevention Branch/Health Studies Branch/Nutritional Biochemistry Brand, U.S. Centers for Disease Control and Prevention, U.S. Dept. of Health and Human Services, Atlanta, GA. http://www.bvsde.paho.org/bvsea/fulltext/torreon.pdf.

Pfaff, G. (1993). Sol-gel synthesis of strontium titanate powders of various compositions J. Mater. Chem. Vol. 3, p.p 721-724.

Pfaff, G. (1994).Synthesis of calcium titanate powders by the sol-gel process. Chem. Mater. Vol. 6 No.1, p.p 58-62.

Plaza, M.G. Pevida, C. Arias, B. Fermoso, J. Casal, M.D. Martín, C.F. Rubiera, F \& Pis J.J. (2009). Development of low-cost biomass-based adsorbents for postcombustion $\mathrm{CO}_{2}$ capture. Fuel. Vol. 88, Issue 12 p.p 2442-2447.

7th European Conference on Coal Research and Its Applications.

Riddell, T. Solon, O. Quimbo, S.A. Tan, C.M, Butrick, E. \& Peabody, J.W. (2007) Elevated blood-lead levels among children living in the rural Philippines. Bulletin of the World. Health Organization 85 (9) P.P 674-682.

Riss, A. Berger, T. Grothe, H. Bernardi, J. Diwald, O. \& Kno1zinger E. (2007). Chemical Control of Photoexcited States in Titanate Nanostructures. Nano Letters 2007 Vol 7. No.2 p.p 433-438.

Ruthven, D.M. (1984).Principles of adsorption and adsorption processes. Wiley Interscience, New York.(USA), 1984.

Schmidt, H.K. Geiter, E. Menning, M. Krug, H. Becker, C. \&. Winkler, R. (2010).The sol- gel process for nano-technologies: New nanocomposites with interesting optical and mechanical properties. 
http:/ / scidok.sulb.uni-saarland.de/volltexte/2010/2895/pdf/sm199812.pdf.

Sperlich, A. Werner, A. Genz. A. Amy, G. Worch, E. \& Jekel, M. (2005).Breakthrough behavior of granular ferric hydroxide (GFH) fixed-bed adsorption filters: modeling and experimental approaches. Water Research Vol.39 p.p 1190-1198.

Tsezos, M. (1984). Recovery of Uranium from Biological Adsorbents- Desorption Equilibrium, Biotechnology AND Bioengineering, Vol. 26, p.p 973-981.

Tong, S. von Schirnding, Y.E \& Prapamontol, T. Environmental lead exposure: a public health problem of global dimensions.Bulletin of the Wordl Health Organization Vol.78 No.9 p.p 1068-1077.

Unal, U. Matsumoto, Y. Tanaka, N. Kimura, Y. \& Tamoto, N.(2003). Electrostatic SelfAssembly Deposition of Titanate(IV) Layered oxides intercalated with transition metal complexes and their electrochemical properties. J. Phys. Chem. B. Vol. 107 (46), p.p 12680-12689.

Wallenberg, L., Sanati, M., \& Andersson, A.(1990). On the transformation Mechanism of $\mathrm{K}_{2} \mathrm{Ti}_{4} \mathrm{O}^{9}$ to $\mathrm{TiO}_{2}$ and Formation of Microvoids, Microsc. Microanal Microstruct. 1:357-364.

Weber, W. (1972). Physicochemical processes for water quality control "Kinetics of Adsorption in Columns of Fluidized Media," J. Water Pollut. Contr. Fed., 37, 4, 425. Weber, WJ, Jr.SERIE: Environmental science and technology, New York Wiley-InterScience.

Xie, G. Y, Zhong, Y. J, Sui, G. X, \& Yang, R. (2010). Mechanical properties and sliding wear behavior of potassium titanate whiskers-reinforced poly(ether ether ketone) composites under water-lubricated condition. Journal of applied polymer science. Vol. 117 issue 1 p.p 186-193

Zhang, S. Dai, Y. Xie, X. Fan, Z. \& Tan, Z. (2005). Study on blood lead level and related risk factors among children aged 0-6 years in 15 cities in China. Journal Zhonghua liu xing bing xue za zhi = Zhonghua liuxingbingxue zazhi Vol. 26 No. 9 p.p 651-654. http:/ / alertaplomo.org

Zhao, M. \& Duncan, J.R. (1998) Bed-depth-service-time analysis on column removal of $\mathrm{Zn}^{2+}$ using Azolla filiculoides. Biotechnology Letters, Vol 20, No 1, , pp. 37-39.

Zhang, S. Chen, Q. \& Peng, L.-M. (2005). Structure and formation of $\mathrm{H}_{2} \mathrm{Ti}_{3} \mathrm{O}_{7}$ nanotubes in an alkali environment. Phys. ReV. B, Condensed matter and materials physics Vol. 71, No. 1. pp. 014104.1-014104.11

Zhuang, G.S., Sui G.X., Meng H., Sun, Z.S. \& R. Yang.(2007). Mechanical properties of potassium titanate whiskers reinforced poly(ether ether ketone) composites using different compounding processes. Composites Science and Technology Vol. 67, Issue 6, p.p 1172-1181..

Wang, Q. Guo, Z. \& Chung, J. (2009) Formation and structural characterization of potassium titanates and the potassium ion exchange property. Materials Research Bulletin Vol. 44 p.p 1973-1977.

Yang, J. Shi, Y. \& Yan, C. (2010). Selective Laser Sintering of Polyamide 12/Potassium Titanium Whisker Composites. Journal of Applied Polymer Science. Vol. 117 No.4 p.p 2196-2204.

Yeh, Y. C., Tseng, T.Y, \& Chang D.A.(2005). Electrical Properties of $\mathrm{TiO}_{2}-\mathrm{K}_{2} \mathrm{Ti}_{6} \mathrm{O}_{13}$ Porous Ceramic Humidity Sensor J. Am. Ceram. Soc., Vol. 73 issue 7. p.p 1992-1998. 


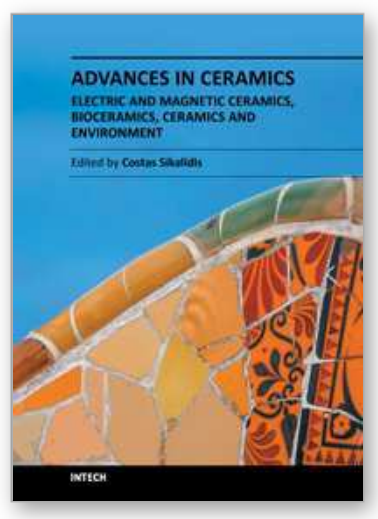

\author{
Advances in Ceramics - Electric and Magnetic Ceramics, \\ Bioceramics, Ceramics and Environment \\ Edited by Prof. Costas Sikalidis
}

ISBN 978-953-307-350-7

Hard cover, 550 pages

Publisher InTech

Published online 06, September, 2011

Published in print edition September, 2011

The current book consists of twenty-four chapters divided into three sections. Section I includes fourteen chapters in electric and magnetic ceramics which deal with modern specific research on dielectrics and their applications, on nanodielectrics, on piezoceramics, on glass ceramics with para-, anti- or ferro-electric active phases, of varistors ceramics and magnetic ceramics. Section II includes seven chapters in bioceramics which include review information and research results/data on biocompatibility, on medical applications of alumina, zirconia, silicon nitride, $\mathrm{ZrO} 2$, bioglass, apatite-wollastonite glass ceramic and b-tri-calcium phosphate. Section III includes three chapters in applications of ceramics in environmental improvement and protection, in water cleaning, in metal bearing wastes stabilization and in utilization of wastes from ceramic industry in concrete and concrete products.

\title{
How to reference
}

In order to correctly reference this scholarly work, feel free to copy and paste the following:

Aguilar González Miguel Angel (2011). Development of Potassium Polytitanates Nanoadsorbents for the Removal of Lead lons from Water - Dynamic Processes, Advances in Ceramics - Electric and Magnetic Ceramics, Bioceramics, Ceramics and Environment, Prof. Costas Sikalidis (Ed.), ISBN: 978-953-307-350-7, InTech, Available from: http://www.intechopen.com/books/advances-in-ceramics-electric-and-magneticceramics-bioceramics-ceramics-and-environment/development-of-potassium-polytitanates-nanoadsorbentsfor-the-removal-of-lead-ions-from-water-dynami

\section{INTECH}

open science | open minds

\section{InTech Europe}

University Campus STeP Ri

Slavka Krautzeka 83/A

51000 Rijeka, Croatia

Phone: +385 (51) 770447

Fax: +385 (51) 686166

www.intechopen.com

\section{InTech China}

Unit 405, Office Block, Hotel Equatorial Shanghai

No.65, Yan An Road (West), Shanghai, 200040, China

中国上海市延安西路65号上海国际贵都大饭店办公楼405单元

Phone: +86-21-62489820

Fax: $+86-21-62489821$ 
(C) 2011 The Author(s). Licensee IntechOpen. This chapter is distributed under the terms of the Creative Commons Attribution-NonCommercialShareAlike-3.0 License, which permits use, distribution and reproduction for non-commercial purposes, provided the original is properly cited and derivative works building on this content are distributed under the same license. 